\title{
A Selective AMPA Antagonist, LY293558, Suppresses Morphine Withdrawal-Induced Activation of Locus Coeruleus Neurons and Behavioral Signs of Morphine Withdrawal
}

Kurt Rasmussen, Ph.D., William T. Kendrick, B.A., Jeffrey H. Kogan, Ph.D., and George K. Aghajanian, M.D.

The glutamate receptor subtype that mediates the morphine withdrawal-induced activation of locus coeruleus (LC) neurons was examined in this study using in vitro and in vivo single-unit electrophysiologic recordings. For $L C$ neurons recorded in vitro in rat brain slices, the selective $\alpha$-amino-3-hydroxy-5-methyl-4-isoxazole proprionic acid (AMPA) antagonist, LY293558, showed a greater than 10fold selectivity for inhibiting the excitatory effects of AMPA vs kainate, and a greater than 30-fold selectivity for inhibiting the excitatory effects of AMPA vs NMDA. $L Y 293558$ also greatly reduced the response of $L C$ neurons to glutamate in a concentration-dependent manner. In in vivo recordings in anesthetized rats, pretreatment with LY293558 (0.1 to $10 \mathrm{mg} / \mathrm{kg}, \mathrm{IP})$ dose dependently suppressed the morphine withdrawal-induced activation of LC neurons. In unanesthetized, morphine-dependent animals, pretreatment with LY293558 (1 to $30 \mathrm{mg} / \mathrm{kg}, \mathrm{IP}$ ) dose dependently suppressed naltrexone-precipitated morphine withdrawal signs. These results indicate: (1) AMPA receptors mediate a large component of the excitatory effects of glutamate on LC neurons; (2) activation of AMPA receptors plays an important role in the morphine withdrawalinduced activation of $L C$ neurons; (3) AMPA antagonists can suppress many signs of morphine withdrawal in awake animals; and (4) AMPA antagonists may have therapeutic effects in humans for the treatment of opiate withdrawal. (C) 1996 American College of Neuropsychopharmacology [Neuropsychopharmacology 15:497-505, 1996]
KEY WORDS: Locus coeruleus; Morphine withdrawal; AMPA; LY 293558

The locus coeruleus (LC) is the largest cluster of noradrenergic neurons in the mammalian brain (Dahlstrom and Fuxe 1965; Foote et al. 1983). Whereas the cell bod-

From the Lilly Research Laboratories (KR, WTK), Eli Lilly \& Co., Indianapolis, Indiana; Departments of Pharmacology (JHK, GKA), and Psychiatry (GKA), Yale University School of Medicine, New Haven, Connecticut.

Address correspondence to: Kurt Rasmussen, Ph.D., Lilly Research Laboratories, Eli Lilly \& Co., Lilly Corporate Center, Indianapolis, IN 46285.

Received January 18, 1996; Revised March 25, 1996; Accepted March 29, 1996. ies are confined to a small area in the pons, LC neurons send extensive projections to most other regions of the central nervous system, including the cerebral cortex, hippocampus, cerebellum, and spinal cord (Jones and Moore 1977; Nygren and Olson 1977). Due to these wide-ranging projections, the $\mathrm{LC}$ is in a position to influence the activity of many parts of the neuraxis simultaneously and has been hypothesized to play a role in a great number of behaviors, physiologic processes, and disease states.

The $L C$ receives afferent projections from a number of sites, including the nucleus paragigantocellularis (PGi), the prepositus hypoglossi, subregions of the hypothalamus, the Kolliker-Fuse nucleus, the periaqua- 
ductal gray, and the mesencephalic reticular formation (Cedarbaum and Aghajanian 1978; Aston-Jones et al. 1986; Luppi et al. 1995). The projection to the LC from the PGi has been hypothesized to have an important influence on the activity of LC neurons and has been demonstrated to provide both inhibitory and excitatory inputs to the LC. The inhibitory inputs from the PGi are mediated, at least in part, via noradrenergic and enkephalinergic projections (Aston-Jones et al. 1992). These inhibitory inputs to the LC from the PGi have been hypothesized to play a role in the inhibition of the LC during REM sleep (Luppi et al. 1995). The excitatory input from the PGi is mediated, at least in part, via glutamatergic projections (Ennis and Aston-Jones 1988) and has been shown to play an important role in the activation of the LC observed during morphine withdrawal (Rasmussen and Aghajanian 1989).

In opiate-dependent rats, there is a marked increase in firing of LC neurons during antagonist-precipitated withdrawal (Aghajanian 1978; Valentino and Wehby 1989; Rasmussen et al. 1990; Akaoka and Aston-Jones 1991). This increase in activity of LC neurons has been hypothesized to play an important role in opiate withdrawal symptoms since: (1) the increased unit activity correlates temporally with withdrawal behaviors (Rasmussen et al. 1990); (2) systemic administration and local infusion of clonidine, an $\alpha_{2}$-adrenergic receptor agonist, into the LC suppresses the increased LC unit activity (Aghajanian 1978), the increase in norepinephrine turnover and release in LC projection areas (Crawley et al. 1979; Laverty and Roth 1980; Done et al. 1992), and many behavioral symptoms (Tseng et al. 1975; Gold et al. 1978; Taylor et al. 1988) seen during opiate withdrawal; (3) destruction of the LC decreases physical signs of opiate withdrawal (Maldonado and Koob 1993); and (4) the most sensitive site for the induction of withdrawal signs after the local injection of an opiate antagonist is the LC (Maldonado et al. 1992). Although intrinsic factors play a role in the withdrawal-induced activation of the LC (Rasmussen et al. 1990; Nestler 1992; Kogan et al. 1992), several lines of evidence support a role for excitatory amino acid afferents in the withdrawal activation of LC neurons. First, nonselective excitatory amino acid antagonists, after both ICV injection or direct infusion into the LC, attenuate the morphine withdrawal-induced activation of LC neurons (Rasmussen and Aghajanian 1989; Rasmussen et al. 1991a; Akaoka and Aston-Jones 1991). Second, opiate withdrawal increases glutamate and aspartate efflux in the LC (Aghajanian et al. 1994; Zhang et al. 1994). In addition, lesions of the PGi attenuate the morphine withdrawal-induced activation of LC neurons (Rasmussen and Aghajanian 1989).

The receptor subtype that mediates the glutamate and morphine withdrawal-induced activation of LC neurons has not been determined. However, it has been demonstrated that the receptors that mediate the excitatory amino acid input from the PGi are non-N-methylD-aspartic acid (NMDA) glutamate receptors (Ennis and Aston-Jones 1988). Consistent with this finding are results indicating that the excitatory amino acid-induced activation of the LC during opiate withdrawal is not mediated primarily through NMDA receptors, as NMDA antagonists do not block the morphine withdrawal-induced activation of the LC (Rasmussen et al. 1991b). However, another study reported that direct injection of an NMDA antagonist into the LC produced a modest $(\backsim 20 \%)$, but significant, reduction in withdrawal-induced activation of the LC (Akaoka and Aston-Jones 1991). In an effort to evaluate further the subtype of glutamate receptor that mediates the glutamate and/or morphine withdrawal-induced activation of LC neurons, we examined the effects of the selective AMPA antagonist LY293558 (Ornstein et al. 1993; Schoepp et al. 1995) on: (1) glutamate-induced excitation of LC neurons in vitro; and (2) morphine withdrawal-induced excitation of LC neurons in vivo. We also examined the effect of LY293558 on morphine withdrawal signs in awake animals.

\section{MATERIALS AND METHODS}

\section{Brain Slice Preparation and In Vitro Electrophysiologic Recordings}

LC brain slices were prepared as previously described (Kogan et al. 1992). In brief, male Sprague-Dawley rats (100 to $200 \mathrm{~g}$; obtained from CAMM, Wayne, NJ) were anesthetized with chloral hydrate $(400 \mathrm{mg} / \mathrm{kg} \mathrm{IP})$ and perfused intracardially with $50 \mathrm{ml}$ of ice-cold $\left(\backsim 4^{\circ} \mathrm{C}\right)$ modified artificial cerebrospinal fluid (ACSF) in which $\mathrm{NaCl}$ is replaced by equiosmolar (calculated) sucrose (sucrose-ACSF). The animals were then decapitated and the brains rapidly removed and placed into icecold sucrose-ACSF where they were trimmed to a small block $\left(\backsim 100 \mathrm{~mm}^{3}\right)$ containing the LC. Coronal slices (600 to $700 \mu \mathrm{mol} / \mathrm{L}$ ) were cut in ice-cold sucrose-ACSF using a vibrating knife microtome (Vibraslice, WPI, Sarasota, FL). Slices containing the LC were transferred onto the stage of a gas-liquid interface brain slice chamber in which a constant flow of humidified $95 \% \mathrm{O}_{2} / 5 \%$ $\mathrm{CO}_{2}$ and ACSF ( $\sim 1 \mathrm{ml} / \mathrm{min}$ ) was maintained throughout the experiment at a temperature of $33 \pm 0.5^{\circ} \mathrm{C}$. The normal ACSF consisted of (in nmol/L): $\mathrm{NaCl}, 126 ; \mathrm{KCl}$, 3; $\mathrm{CaCl}_{2}, 2 ; \mathrm{MgSO}_{4}, 2 ; \mathrm{NaHCO}_{3}, 25 ; \mathrm{NaH}_{2} \mathrm{PO}_{4}, 1.25 ; d-$ glucose, 10 .

The LCs were visually identified by reflected light in the anterior pons as gray, oval areas on the lateral borders of the central gray and fourth ventricle immediately anterior to the genu of the VII nerve. The cells recorded in this study all displayed a slow spontaneous firing rate and regular rhythm ( $\backsim 0.5$ to $1 \mathrm{~Hz}$ ). Single- 
unit extracellular potentials were performed with glass microelectrodes filled with $2 \mathrm{~mol} / \mathrm{L} \mathrm{NaCl}(5$ to $10 \mathrm{M} \Omega$ ). Input voltage was amplified with a high-input impedance amplifier (Axoclamp 2) and monitored by an audioamplifier and an oscilloscope. Firing rates were determined using a window discriminator, and data were collected on a strip chart recorder as integrated time histograms (10-second reset interval). $\mathrm{IC}_{50}$ values were determined using Prism software (Graphpad Software, Inc.).

Drugs were dissolved in ACSF at known concentrations and applied by perfusion through the slice chamber. L-glutamic acid monosodium salt (glutamate) was obtained from Sigma Chemical Co. (St. Louis, MO). ( \pm )- $\alpha$-Amino-3-hydroxy-5-methylisoxazole-4-propionic acid hydrobromide (AMPA), 2-carboxy-4-(1-methylethenyl)-3-pyrrolidinacetic acid (kainate), and N-methyl-Daspartic acid (NMDA) were obtained from Research Biochemicals Inc., (Natick, MA). LY293558 was obtained from Dr. Paul Ornstein (Eli Lilly and Co.)

\section{Opiate Dependence and Withdrawal}

Opiate dependence was induced in male Sprague-Dawley rats (Charles River, 250 to $350 \mathrm{~g}$ ) by the subcutaneous pellet implantation method (Blasig et al. 1973; Way et al. 1969). While under halothane anesthesia, animals were implanted with either morphine pellets (NIDA; 75 $\mathrm{mg}$ morphine base, $68.5 \mathrm{mg}$ microcrystalline cellulose, $1.5 \mathrm{mg}$ magnesium stearate, $2.5 \mathrm{mg}$ colloidal silicon dioxide) or placebo pellets (NIDA; $150 \mathrm{mg}$ Avicel PH-102, $1.5 \mathrm{mg}$ magnesium stearate, $0.75 \mathrm{mg}$ colloidal silicon dioxide, $1.75 \mathrm{mg}$ purified water). Two pellets were implanted per day for 2 days. Withdrawal was induced 48 hours after the last set of pellets was implanted. To ensure steady levels of withdrawal throughout the test period, all four pellets were removed 1 to 2 hours before precipitating withdrawal. Withdrawal was induced by administering the opiate antagonist naltrexone $\mathrm{HCl}(10$ $\mathrm{mg} / \mathrm{kg}$; Sigma) subcutaneously.

\section{Behavioral Ratings}

For the behavioral assessment of opiate withdrawal, animals were studied in clear plexiglass cages (18 in $\times 10$ in $\times 8$ in) and remained in these cages for the entire study. Animals were adapted to the cages for $15 \mathrm{~min}-$ utes and were then administered a pretreatment of either LY293558 or saline $(1 \mathrm{ml} / \mathrm{kg}$, IP). Naltrexone was administered 15 minutes after the pretreatment. Thirteen previously identified behaviors characteristic of the rat opiate abstinence syndrome were assessed (see Himmelsbach et al. 1935; Way et al. 1969; Wei 1973; Blasig et al. 1973; Aceto et al. 1986). The absolute frequency of eight episodic behaviors was recorded and a score was calculated based on multiples of five inci- dents $(0)=$ no incidents; $1=1$ to 5 incidents; $2=6$ to 10 incidents; and $3=11$ to 15 incidents, etc.). Behaviors scored in this manner were teeth chatter (separated by at least 3 seconds), jumping, wet-dog shakes, writhing, stereotyped head movements, tremor, digging, and erections. Chewing (without any matter in the mouth) was similarly scored in multiples of 100 occurrences. Five withdrawal behaviors could not be defined in discrete episodes, and the severity of these behaviors was assessed using a 4-point scale: $0=$ absent; $1=$ mild; $2=$ moderate; 3 = marked. Behaviors rated in this fashion were lacrimation, ptosis, irritability, diarrhea, and salivation. The amount of weight loss was measured at the end of the rating period (i.e., one hour after the administration of naltrexone), and a score was calculated based on multiples of $5 \mathrm{~g}(0=$ no loss; $1=1$ to $5 \mathrm{~g} ; 2=6$ to $10 \mathrm{~g} ; 3=11$ to $15 \mathrm{~g}$, etc.)

\section{In Vivo Electrophysiologic Recordings}

For unit recording, the animals were anesthetized with chloral hydrate ( $400 \mathrm{mg} / \mathrm{kg}$, IP); supplemental doses of anesthetic were administered through a lateral tail vein as needed. Body temperature was maintained at 35 to $37^{\circ} \mathrm{C}$ by a heating pad. Rats were mounted in a stereotaxic apparatus, and a cisternal drainage was performed to help prevent tissue swelling. A burr hole was made $1.2 \mathrm{~mm}$ posterior to lambda and $1.1 \mathrm{~mm}$ lateral to the midline. The recording electrodes were single-barrel glass micropipettes, broken back to a tip diameter of 2 to $3 \mu \mathrm{m}$, and filled with a $2 \mathrm{~mol} / \mathrm{L} \mathrm{NaCl}$ solution. Extracellular single-unit recordings were made in the LC as described previously (Rasmussen et al. 1990). Briefly, LC cells were encountered 5.5 to $6.0 \mathrm{~mm}$ below the dural surface (at the above coordinates), just ventral to a zone of relative electrical silence (corresponding to the IVth ventricle), and just medial to cells of the mesencephalic nucleus of the Vth nerve (which could be activated by depression of the mandible). LC cells were identified by their long duration action potential $(>2$ mseconds), characteristic positive-negative waveform, slow and somewhat regular firing pattern $(0.5$ to $5 \mathrm{~Hz})$, and short-latency burst of excitation followed by an extended ( 1 to 2 second) quiescent period after compression of the contralateral hindpaw. Recordings of stable, spontaneous firing rates were obtained from each neuron for at least 3 minutes. The spontaneous rate of different cells was sampled throughout the LC for 15 minutes before and after the administration of LY293558 and for 90 minutes after the administration of naltrexone.

\section{Statistical Analysis}

Results were analyzed with one-way analysis of variance coupled with Dunnett's post-hoc test or a two-way analysis of variance. 


\section{RESULTS}

\section{In Vitro Elecrophysiologic Recordings}

As illustrated in Figure 1, LY293558 produced a concentration-dependent block of the excitatory effect of glutamate upon $\mathrm{LC}$ neurons. The $\mathrm{IC}_{50}$ values for the blockade of excitatory responses to glutamate $(1 \mathrm{mmol} /$ L), AMPA $(3 \mu \mathrm{mol} / \mathrm{L})$, kainate $(6 \mu \mathrm{mol} / \mathrm{L})$, and NMDA $(100 \mu \mathrm{mol} / \mathrm{L})$ were determined individually in this manner. As can be seen from Table 1, LY293558 was approximately 13-fold more potent in blocking AMPA than kainate and 30-fold more potent in blocking AMPA than NMDA. Figure 1 illustrates the selectivity of LY293558 when tested at a single low concentration ( $3 \mu \mathrm{mol} / \mathrm{L}$ ) against all four excitatory amino acids in the same cell; the response to AMPA was almost totally blocked whereas the responses to NMDA and kainate were virtually unaffected. Thus, in LC neurons, as previously reported in cortical slices (Schoepp et al. 1995), LY293558 or its racemate have selectivity in antagonizing AMPA compared with NMDA and kainate.

\section{In Vivo Electrophysiologic Recordings}

Pretreatment with LY293558 antagonized the increase in LC activity caused by the administration of naltrexone in morphine dependent rats (ANOVA; F $=4.47, p<$
.0001; Figure 2). The firing rates of LC neurons in animals treated with morphine pellets were significantly lower $(p<.05)$ than in animals receiving sham pellets, indicating an incomplete development of tolerance at this time point (Figure 2; baseline). Pretreatment with LY293558 did not change the firing rates of LC neurons in animals receiving either morphine or sham pellets (Figure 2; 0 minutes post naltrexone). After the administration of naltrexone, the firing rates of LC neurons were significantly elevated $(p<.05)$ in saline-pretreated, morphine-pelleted animals at 30,60, and 90 minutes post naltrexone, but not in animals receiving sham pellets (Figure 2). In animals pretreated with $0.1 \mathrm{or} 1.0 \mathrm{mg} /$ $\mathrm{kg}$ LY293558, the firing rates of LC neurons were significantly lower $(p<.05)$ than saline-pretreated, morphinepelleted animals at 30 minutes, but not at 60 and $90 \mathrm{~min}-$ utes, post naltrexone. In animals pretreated with $10.0 \mathrm{mg} /$ $\mathrm{kg}$ LY293558, the firing rates of LC neurons were significantly lower $(p<.05)$ than saline-pretreated, morphinepelleted animals at 30,60 , and 90 minutes post naltrexone and were not significantly different from sham-pelleted animals at 30,60 , and 90 minutes post naltrexone.

\section{Behavioral Ratings}

Pretreatment with LY293558 antagonized morphine withdrawal signs caused by the administration of nal-
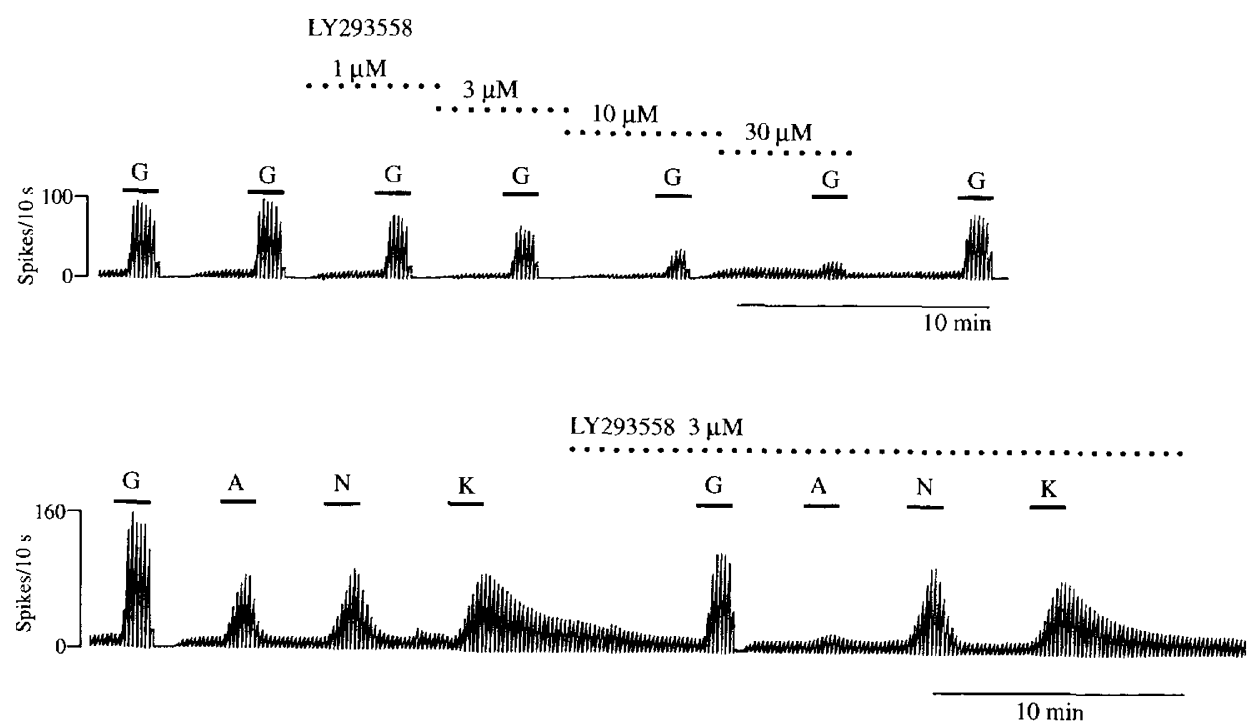

Figure 1. Top: Firing rate histogram from an extracellular recording of a locus coeruleus neuron in a brain slice showing the concentration-dependent effect of LY293558 on glutamate (G) responses. As illustrated in the first two responses, repeated 1-minute glutamate applications $(1 \mathrm{mmol} / \mathrm{L})$ did not cause any decrement in the response by itself. LY293558, bath applied at progressively higher concentrations, greatly reduced the glutamate response. After a 4-minute washout of LY293558, the glutamate response largely recovered. Each vertical line of the rate histogram represents the integrated firing rate, counted as spikes per 10 seconds, and displayed on a chart recorder. Bottom: Firing rate histogram from an extracellular recording of a locus coeruleus neuron in a brain slice showing the selectivity of LY293558 antagonism. 1-minute applications of glutamate (G: $1 \mathrm{mmol} / \mathrm{L}$ ), AMPA (A: $3 \mu \mathrm{mol} / \mathrm{L}), \mathrm{NMDA}(\mathrm{N}: 100 \mu \mathrm{mol} / \mathrm{L})$, and kainate $(\mathrm{K}: 6 \mu \mathrm{mol} / \mathrm{L})$ elicited robust responses. Bath application of LY293558, at an intermediate concentration of $3 \mu \mathrm{mol} / \mathrm{L}$ (see Table 1) caused almost a complete block of the AMPA response, whereas the NMDA and kainate responses were virtually unaffected. The glutamate response was reduced by about $30 \%$. 
Table 1. $\mathrm{IC}_{50}$ Values for the Antagonism of Excitatory Amino Acid Responses on Locus Coeruleus Neurons in Rat Brain Slices by LY293558

\begin{tabular}{lccc}
\hline \multicolumn{1}{c}{ Agonist } & $n$ & $\mathbf{I C}_{\mathbf{5 0}}(\mu \mathbf{m o l} / \mathbf{L})$ & $\begin{array}{c}\text { 95\% Confidence Interval } \\
\mathbf{I C}_{\mathbf{5 0}}(\mu \mathbf{m o l} / \mathbf{L})\end{array}$ \\
\hline AMPA $(3 \mu \mathrm{mol} / \mathrm{L})$ & $5-6$ & 0.8 & 0.7 to 0.9 \\
Glutamate $(1 \mathrm{mmol} / \mathrm{L})$ & 5 & 4.8 & 3.8 to 6.0 \\
Kainate $(6 \mu \mathrm{mol} / \mathrm{L})$ & 5 & 10.5 & 4.8 to 22.9 \\
NMDA $(100 \mu \mathrm{mol} / \mathrm{L})$ & 4 & 24.7 & 19.0 to 32.0 \\
\hline
\end{tabular}

trexone in morphine dependent rats as reflected in the composite withdrawal score (ANOVA; $\mathrm{F}=3.93, p<$ .0001; Figure 3). A significant reduction of many of the individual symptoms that contributed to the overall withdrawal score was also observed. Pretreatment with LY293558 led to a significant $(p<.05)$ reduction in writhes, wet-dog shakes, stereotyped head movements, ptosis, lacrimation, salivation, diarrhea, and chews, whereas there was no significant change in the occurrence of teeth chatter, jumps, tremor, irritability, erections, digging, and the amount of weight loss (Table 2). The doses of LY293558 used in this study had no signif-

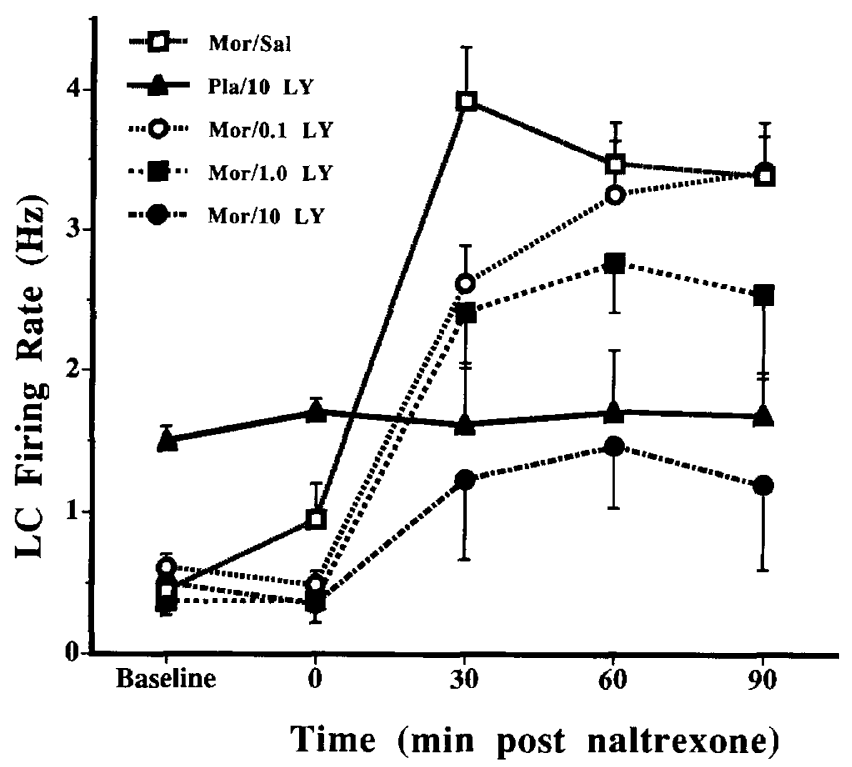

Figure 2. The activity of locus coeruleus (LC) neurons during naltrexone-induced withdrawal in morphine(Mor)dependent, anesthetized rats pretreated with saline (Sal) (Mor/Sal; open squares), $0.1 \mathrm{mg} / \mathrm{kg}$ LY293558 (LY;IP) (Mor/ $0.1 \mathrm{LY}$; open circles), $1.0 \mathrm{mg} / \mathrm{kg} \mathrm{LY}$ (Mor/1.0 LY; closed squares), or $10 \mathrm{mg} / \mathrm{kg} \mathrm{LY}$ (Mor/10 LY; closed circles). The activity of LC neurons in animals receiving placebo (Pla) pellets and treatment with $10 \mathrm{mg} / \mathrm{kg} \mathrm{LY}$ followed by naltrexone is also shown (Pla/10 LY; closed triangles). Values are expressed as mean $\pm \mathrm{SE}$ (some error bars omitted for clarity; $n=2$ to 26 neurons at each time point). See test for significant differences. icant effect on locomotor activity or the righting reflex. At doses of $50 \mathrm{mg} / \mathrm{kg}$ and above, animals displayed an impaired gait and a delayed righting reflex (data not shown).

\section{DISCUSSION}

For LC neurons recorded in brain slices, LY293558 showed a greater than 10 -fold selectivity for inhibiting the excitatory effects of AMPA vs kainate, and a greater than 30-fold selectivity for inhibiting the excitatory effects of AMPA vs NMDA. These results are similar to those obtained with LY293558 (and its racemate LY215490) in antagonizing the effects of AMPA, kainate, and NMDA

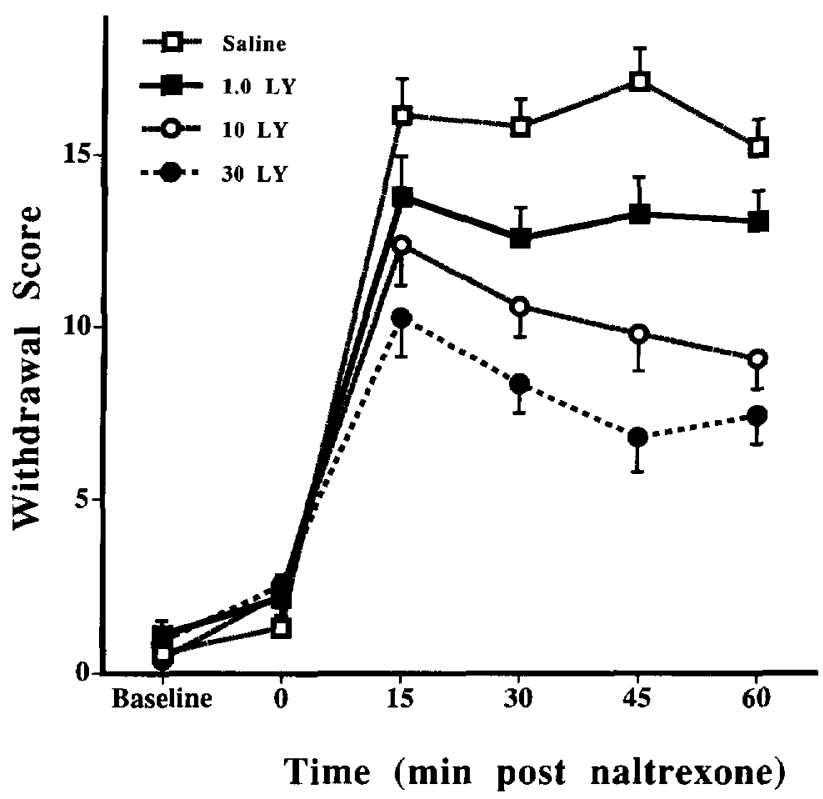

Figure 3. Effects of pretreatment with saline (open squares; $n=12$ ) or $1.0 \mathrm{mg} / \mathrm{kg}$ LY293558 (LY; IP) (1.0 LY; closed squares; $n=10), 10.0 \mathrm{mg} / \mathrm{kg}$ LY (10 LY; open circles; $n=10)$, or $30 \mathrm{mg} / \mathrm{kg}$ LY (30 LY; closed circles; $n=11$ ) LY293558 (LY; IP) on naltrexone-precipitated withdrawal signs in morphine-dependent rats. Values are expressed as mean $\pm \mathrm{SE}$ (some error bars omitted for clarity). See text for significant differences. 


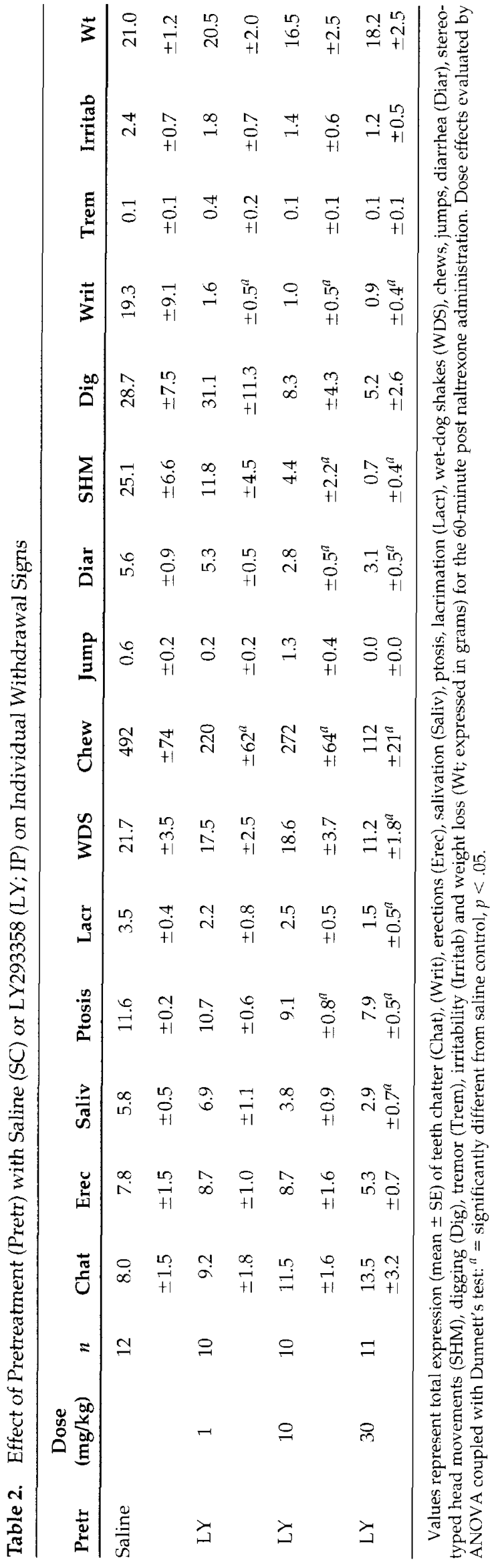

in rat cerebral cortical slices (Schoepp et al. 1995). LY293558 also greatly reduced the response of LC neurons to glutamate in a concentration-dependent manner. These results indicate than AMPA receptors play a major, but not exclusive, role in mediating the excitatory effects of glutamate on LC neurons.

Because the morphine withdrawal-induced activation of the LC has been hypothesized to be mediated primarily by glutamate, we examined the effects of LY293558 on the activity of LC neurons during morphine withdrawal. Administration of LY293558 antagonized the morphine withdrawal-induced activation of the LC neurons in a dose-dependent manner. Thus, the morphine withdrawal-induced activation of the LC appears to be mediated primarily by glutamate acting through AMPA receptors. However, because the exact brain concentration of LY293558 was not measured in this study, it is possible that the higher doses of LY293558 may have lost some selectivity for AMPA receptors and affected kainate or NMDA receptors. Previous studies have shown that NMDA receptors mediate little, if any, of the withdrawal-induced excitation of the LC (Rasmussen et al. 1991b; Akaoka and Aston-Jones 1991). Thus, additional studies examining the selective effects of LY293558 in vivo on kainate and AMPA responses in the LC would help to rule out any contribution of antagonism of kainate receptors to the effects of LY293558 on withdrawal-induced activation of the LC. It is important to note that at the highest dose of LY293558 tested in this study $(10 \mathrm{mg} / \mathrm{kg})$, LC neurons displayed an increase in activity during morphine withdrawal to control levels. It is possible that a higher dose of LY293558 may block this small increase to control values. However, this increase to control levels is similar to the increased activity seen in LC cells during morphine withdrawal after the administration of the nonselective glutamate antagonist kynurenic acid (Rasmussen and Aghajanian 1989; Rasmussen et al. 1991a) and is also similar to the increased activity seen in LC cells recorded in brain slices from morphine-dependent rats (Kogan et al. 1992). This component of the withdrawal-induced activation of LC cells may be due to intrinsic (i.e., intracellular) factors (e.g., up-regulated c-AMP pathway-Rasmussen et al., 1990; Nestler 1992) and thus may be insensitive even to higher doses of LY293558.

Because the increased activity of the LC may play an important role in the genesis of some morphine withdrawal signs, we also examined the effects of LY293558 in animals undergoing morphine withdrawal. Pretreatment with LY293558 significantly reduced the signs of morphine withdrawal in awake animals. Significant decreases in the occurrence of writhes, wet-dog shakes, stereotyped head movements, ptosis, lacrimation, salivation, diarrhea, and chews were observed after pretreatment with LY293558. A strong trend toward a sig- 
nificant decrease in the occurrence of digging that did not reach significance was also observed (Table 2). No significant change in the occurrence of teeth chatter, irritability, erections, or the amount of weight loss was observed. No significant changes in the occurrence of jumps and tremors were observed either; however, these two signs occurred with such a low frequency as to make a significant reduction difficult to achieve. It is unlikely that the blockade of withdrawal symptoms produced by LY293558 is due to a nonspecific depressant action, as the doses used in this study did not affect the animals' locomotor activity or righting reflex. Whether higher doses of LY293558 would have had significant effects on additional withdrawal signs is difficult to determine, as higher doses of LY293558 ( $\geq 50$ $\mathrm{mg} / \mathrm{kg}$ ) produced impairment of motor activity.

Whereas the LC appears to be one site of action for LY293558 in decreasing morphine withdrawal signs, AMPA receptors in other brain regions may also play a role. As a number of brain sites have been hypothesized to play an important role in the generation of morphine withdrawal signs, LY293558 may have activity in a number of additional sites to affect the expression of morphine withdrawal signs. Other potential brain sites include those with the highest density of AMPA receptors (i.e., hippocampus, layers I-III of the cortex, dorsal lateral septum, striatum, and the molecular layer of cerebellum; Monaghan et al. 1984; Young and Fagg 1990) and other areas thought to mediate various signs of morphine withdrawal (i.e., spinal cord, central gray, hypothalamus, raphe magnus, and amygdala; Maldonado et al. 1992). Studies using local injections of LY293558 or the blockade of withdrawal-induced c-fos activation by LY293558 could help determine other brain sites where AMPA receptors play an important role in the expression of opiate withdrawal. In addition, some opiate withdrawal signs have been hypothesized to be mediated in the periphery (e.g., diarrhea, salivation, and lacrimation; Bianchetti et al. 1986; Maldonado et al. 1992). Because AMPA receptors have been localized in at least some peripheral organs (i.e., pancreasBertrand et al. 1993) it is possible that the effects of LY293558 on some withdrawal signs are due to blockade of peripheral AMPA receptors. Whereas these central and peripheral AMPA receptors located outside the LC may contribute to the antagonism of morphine withdrawal symptoms, they may also contribute to dose-limiting side effects (e.g., sedation, motor impairment). Thus, clinical trials will be needed to determine if AMPA antagonists can have therapeutic effects in opiate-dependent patients at doses that do not produce significant side effects.

The dose of LY293558 that was able to suppress most of the withdrawal-induced activation of LC neurons in anesthetized animals (i.e., $10 \mathrm{mg} / \mathrm{kg}$ ) only suppressed the physical signs of opiate withdrawal by about $50 \%$.
There are several potential explanations for this difference. One, the elevation in LC activity due to intrinsic factors cannot be blocked by LY293558 (see Figure 2); this modest elevation in firing rate may contribute to the genesis of withdrawal symptoms. Two, it is difficult to compare the effects of a compound in anesthetized vs unanesthetized animals. For example, higher doses of the LY293558 may be required to suppress the activation of the LC in awake animals. Three, LY293558 can suppress the signs of morphine withdrawal through actions in other brain areas in addition to the LC. Indeed, experiments examining c-fos expression during morphine withdrawal indicate that NMDA antagonists and clonidine may exert some of their suppression of morphine withdrawal symptoms through actions in the amygdala and nucleus accumbens (Rasmussen et al. 1995). Four, the LC activation may contribute to some aspect of morphine withdrawal not measured in this study (e.g., aversive effects-Stinus et al. 1990: Kosten 1994). In addition, a combination of these explanations is also possible.

If the modest withdrawal-induced elevation of LC firing rate seen after pretreatment with LY293558 (which may be due to intrinsic changes in the c-AMP system in LC neurons-Rasmussen et al. 1990; Kogan et al. 1992; Nestler 1992) contributes to the genesis of withdrawal symptoms, a blockade of this component of the increased LC activity may provide a more complete suppression of opiate withdrawal signs. Clonidine, by virtue of its activation of $\alpha_{2}$-adrenergic receptors negatively coupled to G-proteins (and subsequent inhibition of the c-AMP system) could provide a suppression of this "intrinsic" component of the withdrawal-induced elevation of LC firing. Thus, combined treatment with clonidine and LY293558 may be able to act synergistically to suppress the withdrawal-induced elevation of LC firing and produce a more complete suppression of morphine withdrawal signs. Furthermore, because both clonidine and LY293558 produce unfavorable side effects at high doses, a combination of modest doses of the two treatments may prove especially useful for the treatment of opiate withdrawal signs in humans.

In conclusion, these data indicate that the excitatory effect of glutamate in the LC is mediated largely, but not completely, through AMPA receptors. This AMPAinduced excitation of LC cells plays an important role in the morphine withdrawal-induced activation of LC neurons. In addition, AMPA antagonists can suppress many signs of morphine withdrawal and have promise as a therapeutic for the relief of opiate withdrawal symptoms in humans.

\section{REFERENCES}

Aceto MD, Dewey WL, Portoghese PS, Takemori AE (1986): Effects of b-flu-naltrexamine (b-FNA) on morphine 
dependence in rats and monkeys. Eur J Pharmocol 123:387-393

Aghajanian GK (1978): Tolerance of locus coeruleus neurones to morphine and suppression of withdrawal response by clonidine. Nature 276:186-187

Aghajanian GK, Kogan JH, Moghaddam B (1994): Opiate withdrawal increases glutamate and aspartate efflux in the locus coeruleus: An in vivo microdialysis study. Brain Res 636:126-130

Akaoka H, Aston-Jones GA (1991): Opiate withdrawalinduced hyperactivity of locus coeruleus neurons is substantially mediated by augmented excitatory amino acid input. J Neurosci 11:3830-3839

Aston-Jones G, Ennis M, Pieribone VA, Nickell WT, Shipley MT (1986): The brain nucleus locus coeruleus: Restricted afferent control of a broad efferent network. Science 234:734-737

Aston-Jones G, Astier B, Ennis M (1992): Inhibition of locus coeruleus noradrenergic neurons by $\mathrm{C} 1$ adrenergic cells in the rostral ventral medulla. Neuroscience 48:371-382

Bertrand G, Gross R, Puech R, Loubatieres-Mariani M-M, Bockaert J (1993): Glutamate stimulates glucagon secretion via an excitatory amino acid receptor of the AMPA subtype in rat pancreas. Eur J Pharmacol 237:45-50

Bianchetti A, Guidice A, Nava F, Manara L (1986): Dissociation of morphine withdrawal diarrhea and jumping in mice by the peripherally selective opioid antagonist SR 58002 C. Life Sci 39:2297-2301

Blasig J, Herz A, Reinhold K, Sieglgansberger S (1973): Development of physical dependence on morphine in respect to time and dosage and quantification of the precipitated withdrawal syndrome in rats. Psychopharmacologia 33:19-33

Cedarbaum JM, Aghajanian GK (1978): Afferent projections to the rat locus coereleus as determined by a retrograde tracing technique. J Comp Neurol 178:1-16

Crawley JN, Laverty R, Roth R (1979): Clonidine reversal of increased norepinephrine metabolite levels during morphine withdrawal. Eur J Pharmacol 57:247-250

Dahlstrom A, Fuxe K (1965): Evidence for the existence of monoamine-containing neurons in the central nervous system. I. Demonstration of monoamines in the cell bodies of brainstem neurons. Acta Physiol Scand Suppl 232:1-55

Done C, Silverstone P, Sharp T (1992): Effect of naloxoneprecipitated morphine withdrawal on noradrenaline release in rat hippocampus in vivo. Eur J Pharmacol 215:333-336

Ennis M, Aston-Jones G (1988): Activation of locus coeruleus from nucleus paragigantocellularis: A new excitatory amino acid pathway in brain. J Neurosci 8:3644-3657

Foote SL, Bloom FE, Aston-Jones G (1983): Nucleus locus coeruleus: New evidence of anatomical and physiological specificity. Physiol Rev 63:844-914

Gold MS, Redmond DE Jr, Kleber HD (1978): Clonidine blocks acute opiate-withdrawal symptoms. Lancet 2 : 599-602

Himmelsbach CK, Gerlach GH, Stanton EJ (1935): A method for testing addiction, tolerance, and abstinence in the rat. J Pharmacol Exp Ther 53:179-188
Jones BE, Moore RY (1977): Ascending projections of the locus coeruleus in the rat. II. Autoradiographic study. Brain Res 127:23-53

Kogan JH, Nestler EJ, Aghajanian GK (1992): Elevated basal firing rates and enhanced responses to 8 -Br-cAMP in locus coeruleus neurons in brain slices from opiatedependent rats. Eur J Pharmacol 211:47-53

Kosten TA (1994): Clonidine attenuates conditioned aversion produced by naloxone-precipitated opiate withdrawal. Eur J Pharmacol 254:59-63

Laverty R, Roth RH (1980): Clonidine reverses the increased norepinephrine turnover during morphine withdrawal in rats. Brain Res 182:482

Luppi P-H, Aston-Jones G, Akaoka H, Chouvet G, Jouvet M (1995): Afferent projections to the rat locus coeruleus demonstrated by retrograde and anterograde tracing with cholera-toxin B subunit and phaseolus vulgaris leucoagglutinin. Neuroscience 65:119-160

Maldonado R, Koob GF (1993): Destruction of the locus coeruleus decreases physical signs of opiate withdrawal. Brain Res 605:128-138

Maldonado R, Stinus L, Gold LH, Koob GF (1992): Role of different brain structures in the expression of the physical morphine withdrawal syndrome. J Pharmacol Exp Ther 261:669-677

Monaghan DT, Yao D, Cotman CW (1984): Distribution of [3H]AMPA binding sites in rat brain as determined by quantitative autoradiography. Brain Res 324:160-164

Nestler EJ (1992): Molecular mechanisms of drug addiction. J Neurosci 12:2439-2450

Nygren LG, Olson L (1977): A new major projection from locus coeruleus: The main source of noradrenergic nerve terminals in the ventral and dorsal columns of the spinal cord. Brain Res 132:85-93

Ornstein PL, Arnold MB, Augenstein NK, Lodge D, Leander JD, Schoepp DD (1993): (3SR,4aRS,6RS,8aRS)-6-[291Htetrazol-5-yl]ethyl]decahydro-isoquinoline-3-carboxylic acid: A structurally novel, systemically active, competitive AMPA receptor antagonist. J Med Chem 36:20462048

Rasmussen K, Aghajanian GK (1989): Withdrawal-induced activation of locus coeruleus neurons in opiate-dependent rats: Attenuation by lesions of the nucleus paragigantocellularis. Brain Res 505:346-350

Rasmussen K, Beitner DB, Krystal JH, Aghajanian GK, Nestler EJ (1990): Opiate withdrawal and the rat locus coereleus: Behavioral, electrophysiological and biochemical correlates. J Neurosci 10:2308-2317

Rasmussen K, Krystal JH, Aghajanian GK (1991a): Excitatory amino acids and morphine withdrawal: Differential effects of central and peripheral kynurenic acid administration. Psychopharmacology 105:508-512

Rasmussen K, Fuller RW, Stockton ME, Perry KW, Swinford RM, Ornstein PL (1991b): NMDA receptor antagonists suppress behaviors but not norepinephrine turnover or locus coeruleus unit activity induced by opiate withdrawal. Eur J Pharmacol 117:9-16

Rasmussen K, Brodsky M, Inturrisi CE (1995): NMDA antagonists and clonidine block c-fos expression during morphine withdrawal. Synapse 20:68-74 
Schoepp DD, Lodge D, Bleakman D, Leander JD, Tizano JP, Wright RA, Palmer AJ, Salhoff CR, Ornstein PL (1995): In vitro and in vivo antagonism of AMPA receptor activation by $(3 S, 4 a R, 6 \mathrm{R}, 8 \mathrm{aR})-6-[2-(1(2) \mathrm{H}$-tetrazole-5-yl)ethyl] decahydroisoquinoline-3-carboxylic acid. Neuropharmacology 34:1159-1168

Stinus IL, Le Moal M, Koob GF (1990): Nucleus accumbens and amygdala are possible substrates for the aversive stimulus effects of opiate withdrawal. Neuroscience 37:767-773

Taylor JR, Elsworth JD, Garcia EJ, Grant SJ, Roth RH, Redmond DE Jr (1988): Clonidine infusion into the locus coeruleus attenuates behavioral and neurochemical changes associated with naloxone-precipitated withdrawal. Psychopharmacology 96:121-134

Tseng L-F, Loh HH, Wei ET (1975): Effects of clonidine on morphine withdrawal signs in the rat. Eur J Pharmacol 30:93-99
Valentino RJ, Wehby RG (1989): Locus coeruleus discharge characteristics of morphine-dependent rats: Effects of naltrexone. Brain Res 488:126-134

Way EL, Loh HH, Sehn F-H (1969): Simultaneous quantitative assessment of morphine tolerance and physical dependence. J Pharmacol Exp Ther 167:1-8

Wei E (1973): Assessment of precipitated abstinence in morphine-dependent rats. Psychopharmacologia (Berl) 28: $35-44$

Young AB, Fagg GE (1990): Excitatory amino acid receptors in the brain: Membrane binding and receptor autoradiographic approaches. Trends Pharmacol Sci 11:126-133

Zhang T, Feng Y, Rockhold RW, Ho IK (1994): Naloxoneprecipitated morphine withdrawal increases pontine glutamate levels in the rat. Life Sci 55:PL25-31 